\title{
Is it safe to nest near conspicuous neighbours? Spatial patterns in predation risk associated with the density of American Golden-Plover nest
}

Marie-Andrée Giroux, Myriam Trottier-Paquet, Joël Bêty, Vincent Lamarre, Nicolas Lecomte

Predation is one of the main factors explaining nesting mortality in most bird species. Birds can avoid nest predation or reduce predation pressure by breeding at higher latitude, showing anti-predator behaviour, selecting nest sites protected from predators, and nesting in association with protective species. American Golden-Plovers (Pluvialis dominica) defend their territory by using various warning and distraction behaviours displayed at varying levels of intensity (hereafter "conspicuous behaviour"), as well as more aggressive behaviours such as aerial attacks, but only in some populations. Such antipredator behaviour has the potential to repel predators and thus benefit the neighbouring nests by decreasing their predation risk. Yet, conspicuous behaviour could also attract predators by signalling the presence of a nest. To test for the existence of a protective effect associated with the conspicuous antipredator behaviour of American Golden-Plovers, we studied the influence of proximity to plover nests on predation risk of artificial nests on Igloolik Island (Nunavut, Canada) in July 2014. We predicted that the predation risk of artificial nests would decrease with proximity to and density of plover nests. We monitored 18 plover nests and set 35 artificial nests at 30, 50, 100, 200, and $500 \mathrm{~m}$ from seven of those plover nests. We found that predation risk of artificial nests increases with the density of active plover nests. We also found a significant negative effect of the distance to the nearest active protector nest on predation risk of artificial nests. Understanding how the composition and structure of shorebird communities generate spatial patterns in predation risks represents a key step to better understand the importance of these species of conservation concern in tundra food webs. 
1

2

3

4

5

6

7

8

9

10

11

12

13

14

15

16

17

18

19
Marie-Andrée Giroux

Université du Québec à Rimouski

Département de biologie

300, Allée des Ursulines

Rimouski, QC

Canada G5L 3A1

Is it safe to nest near conspicuous neighbours? Spatial patterns in predation risk associated with the density of American Golden-Plover nests

Marie-Andrée Giroux ${ }^{1,2,3,4,5}$, Myriam Trottier-Paquet ${ }^{1,3,4}$, Joël Bêty²,3, Vincent Lamarre ${ }^{1,3}$ and Nicolas Lecomte $1,3,4$

${ }^{1}$ Canada Research Chair in Polar and Boreal Ecology, Université de Moncton, Moncton, NB, Canada

${ }^{2}$ Canada Research Chair on Northern Biodiversity, Université du Québec à Rimouski, Rimouski, QC, Canada

${ }^{3}$ Centre d'Études Nordiques \& Département de Biologie, Université du Québec à Rimouski, 


\section{Abstract}

21 Predation is one of the main factors explaining nesting mortality in most bird species. Birds can avoid nest predation or reduce predation pressure by breeding at higher latitude, showing antipredator behaviour, selecting nest sites protected from predators, and nesting in association with protective species. American Golden-Plovers (Pluvialis dominica) defend their territory by using various warning and distraction behaviours displayed at varying levels of intensity (hereafter “conspicuous behaviour”), as well as more aggressive behaviours such as aerial attacks, but only in some populations. Such antipredator behaviour has the potential to repel predators and thus benefit the neighbouring nests by decreasing their predation risk. Yet, conspicuous behaviour could also attract predators by signalling the presence of a nest. To test for the existence of a protective effect associated with the conspicuous antipredator behaviour of American GoldenPlovers, we studied the influence of proximity to plover nests on predation risk of artificial nests on Igloolik Island (Nunavut, Canada) in July 2014. We predicted that the predation risk of artificial nests would decrease with proximity to and density of plover nests. We monitored 18 plover nests and set 35 artificial nests at 30,50,100,200, and $500 \mathrm{~m}$ from seven of those plover nests. We found that predation risk of artificial nests increases with the density of active plover nests. We also found a significant negative effect of the distance to the nearest active protector nest on predation risk of artificial nests. Understanding how the composition and structure of shorebird communities generate spatial patterns in predation risks represents a key step to better understand the importance of these species of conservation concern in tundra food webs. 
40 Predation is one of the main factors causing nesting mortality in most bird species (Ricklefs

41 1969), and hence represents a selective force that induced the development of strategies for

42 minimizing nest predation (Smith et al. 2007b). Predation pressure in birds can be reduced as a

43 result of various responses observed at the species and individual levels, such as breeding at

44 higher latitude (McKinnon et al. 2010a), showing anti-predator behaviour (e.g. Simmons 1952),

45 selecting nest sites protected from predators, and nesting in association with protective species

46 (Haemig 2001, Quinn and Ueta 2008). For instance, several studies showed that predation risk

47 increases with the distance to the nest of aggressive or territorial species such as Snowy Owl

48 (Bubo scandiacus; Bêty et al. 2001), Goshawk (Accipiter gentilis; Mönkkönen et al. 2007),

49 Hooded Crow (Corvus corone cornix; Roos 2002), and Northern Lapwing (Vanellus vanellus;

50 Elliot 1985).

51 Shorebirds, particularly the biggest species with colourful plumage and both parents contributing

52 to parental care, are known to display various behaviours to protect their nests (e.g. Drury 1961,

53 Sordahl 1981, McCaffery 1982, Larsen et al. 1996). The American Golden-Plover (Pluvialis

54 dominica, hereafter "plover") is an example of a shorebird species protecting its nest by using a

55 suite of warning and distraction behaviours displayed at varying levels of intensity, as well as

56 more aggressive behaviour such as aerial attacks in some populations (reviewed in Johnson and

57 Connors 2010). Such behaviour could decrease predation risks for other species nesting nearby,

58 as shown in another arctic-nesting plover species, the Black-bellied Plover (Pluvialis squatarola;

59 Larsen and Grundetjern 1997). Yet, this conspicuous behaviour could also attract predators by

60 signalling the presence of a nest (Paulson and Erckmann 1985). For instance, nesting near a

61 species displaying a conspicuous and aggressive behaviour like the Sabine's Gull (Xema sabini)

62 can decrease nest survival of Red Phalaropes (Phalaropus fulicarius) in years of high predation 
63 pressure (Smith et al. 2007b). The nest density of the species using conspicuous and sometimes

64 aggressive antipredator behaviour could also shape patterns in predation risks for nearby nests.

65 The direction of a density effect would depend on whether the increased nest density better repel 66 (Andersson and Wiklund 1978) or attract predators (Paulson and Erckmann 1985, Schmidt and

67 Whelan 1999, Varela et al. 2007). Nests of arctic-breeding birds, including American Golden-

68 Plovers, are mainly depredated by Arctic Foxes (Vulpes lagopus) and avian predators such as

69 Common Raven (Corvus corax), Glaucous Gull (Larus hyperboreus), and Long-Tailed Jaeger

70 (e.g. Bêty et al. 2002, Lecomte et al. 2008). In addition to bird nests, all of these predators forage

71 on the cyclical lemmings, and the foraging intensity of these predators on bird nests increases in

72 lemming crash years (Bêty et al. 2002; McKinnon et al. 2013). Because many arctic-nesting

73 shorebird species are currently experiencing dramatic declines across their range (Morrison et al.

74 2001, Gratto-Trevor et al. 2011), studying the influence of these species on spatial structures in

75 nest predation risks may shed light on factors favouring nesting associations between arctic-

76 nesting species.

77 The purpose of the study is to test the hypothesis that the American Golden-Plover can generate

78 spatial structure in predation risks within tundra ecosystems. Based on the results obtained with a

79 congener species, the Black-bellied Plover (Larsen and Grundetjern 1997), we predict that nest

80 predation risks decrease with 1) the proximity to a plover nest and 2) the density of plover nests.

81 To test the existence of such a protective effect, we conducted an experimental study with 82 artificial nests in a High-Arctic breeding site. 


\section{Methods}

84 Study area and species

85 We conducted the study on Igloolik Island, Nunavut, Canada $\left(69.39^{\circ} \mathrm{N}, 81.55^{\circ} \mathrm{W} ; 103 \mathrm{~km}^{2}\right)$ in

86 July 2014 (Fig. 1). There, the tundra landscape is mainly composed of raised beaches with little

87 vegetation, Dryas-lichen slopes, and grass-sedge wet and dry meadows (Forbes et al. 1992). The

88 average annual temperature for the period of $1981-2010$ was $-12.9{ }^{\circ} \mathrm{C}$ with the warmest month

89 (July) averaging $7.6^{\circ} \mathrm{C}$ (Environment Canada 2015). These temperatures and vegetation features

90 correspond to a High-Arctic climate.

91 Igloolik Island is a known breeding site for up to 33 bird species, including shorebirds, 92 waterfowl, and seabirds (Lecomte and Giroux 2015). Shorebird nest density on the Island was

9353.5 nests. $\mathrm{km}^{-2}$ for our study (Lecomte and Giroux, unpubl. data). The proximity to the cliffs of 94 Coxe Islands (ca. $15 \mathrm{~km}$ away) and to a polynya (ca. $1.5 \mathrm{~km}$ away) allow numerous cliff breeders 95 as well as offshore and pelagic species to use our study area as a foraging and resting site. The 96 following nest predators are found on the Island: Arctic Foxes, Ermines (Mustela erminea), 97 Parasitic (Stercorarius parasiticus) and Long-Tailed Jaegers, Glaucous Gulls, and Common 98 Ravens (Ellis and Evans 1960, Forbes et al. 1992, Lecomte and Giroux, unpubl. data). 
99 Every year since 2013, we conduct live trapping of lemmings (Collared Lemming, Dycrostonyx

100 groenlandicus; brown lemming, Lemmus lemmus) on the study area to determine their

101 abundance. The trapping takes place for five days in late June-early July by setting up 50

102 Sherman traps at every second intersection (20 m spacing between intersections) of a $200 \mathrm{~m} \mathrm{x}$

$103200 \mathrm{~m}$ grid. After the initial set-up, the traps are visited every 4-6 hours for 56 hours (total of 12

104 visits). The total number of lemmings captured varies greatly from year to year and ranges from

105 0-46. In 2014, no lemming was captured, which means that lemming abundance was most likely

106 very low during bird nesting season.

107 American Golden-Plover nests typically contain four eggs, and both parents incubate the nests

108 during 25 to 27 days (Johnson and Connors 2010). On Igloolik Island, nest success of American

109 Golden-Plover nest varied between 67\% and 92\% (Lecomte and Giroux, unpublished data).

110 Experimental design

111 To evaluate the protection effect of American Golden-Plovers on their neighbouring nests, 35

112 artificial nests were placed at different distances from seven plover nests. Each artificial nest

113 consisted of a hen egg placed in an empty nest cup found in the tundra. We used the protocols

114 used in previous studies to determine the ranges of distance from plover nests (Larsen and

115 Grundetjern 1997, Bêty et al. 2001) and the frequency of visits (Bêty et al. 2001, Nguyen et al.

116 2006, Lecomte et al. 2008, Lecomte et al. 2009). The artificial nests were placed along a linear

117 transect at 30, 50, 100, 200, and $500 \mathrm{~m}$ from active plover nests (Fig. 1). We selected the

118 orientation of the transect randomly by drawing a number between 0 and $360^{\circ}$. Artificial nests

119 were marked in the same way as the natural nests with two wooden sticks and a blue flag placed

1201,5 , and $10 \mathrm{~m}$ north of the nest. Artificial nests were deployed with rubber gloves between 12:00 
121 and 18:00 on 7 and 8 July and checked after $1,2,4,6,8$, and 12 days of exposure. The nests

122 were considered depredated when their egg was missing or broken.

123 In addition to the linear distance (in $\mathrm{m}$ ) to the associated plover nest, we recorded the following 124 variables: linear distance to the closest active plover nest (in $\mathrm{m}$ ), density of active plover nests 125 within a radius of $250 \mathrm{~m}$ around the artificial nest (Fig. 1; American Golden-Plovers start to 126 respond to predators at 200-300m, Byrkjedal 1987a), habitat type (wetland or mesic tundra), and 127 vertical nest concealment (estimated for all nests on 20 July). The distance to the closest active 128 nest became different from the linear distance to the associated plover nest when the associated 129 plover nest was depredated because the latter became inactive. Nest density, nesting success, the 130 type of nesting habitat (wetland or mesic tundra) were evaluated following the Arctic Shorebird 131 Demographic Network protocol (Brown et al. 2014) within an extensive survey zone of 11.7

$132 \mathrm{~km}^{2}$. Vertical nest concealment corresponded to the percent of the nest obscured when viewed 133 through an ocular tube (PVC pipe, $4 \mathrm{~cm}$ diameter $\mathrm{x} 11 \mathrm{~cm}$ length) from $1 \mathrm{~m}$ directly above the 134 nest.

135 The experiment and field protocols were approved by the Université de Moncton Animal Care 136 Committee (permit \# 14-05), by the Department of Environment - Government of Nunavut 137 (permit \# WL-2014-039), and by the Canadian Wildlife Service (permits \#NUN-SCI-14-04).

\section{Statistical Analysis}

139 We modelled the variations in predation risk on artificial nests (response variable) using mixed140 effect Cox proportional hazard regression models (library coxme; Therneau 2012), including the 141 following predictor variables: distance to the associated plover nest (linear and quadratic terms), 
142 distance to the closest active plover nest (linear and quadratic terms), density of active plover

143 nests within a radius of $250 \mathrm{~m}$ around the artificial nest, habitat type, and vertical concealment.

144 We included the artificial and natural nest identity as random terms. Mixed-effect Cox

145 proportional hazard regression models estimate the relationship between Kaplan-Meier survival

146 estimates and the response variables. The exponent of the parameter estimate for each response

147 variable provides the estimate of the hazard ratio, which corresponds to the hazard risk (or 148 predation risk in our study) relative to a baseline measure of risk.

149 We used a model selection approach (Burnham and Anderson 2002) to identify the combination 150 of these variables that best described variations in the predation risk of artificial nests. We 151 compared 24 biologically plausible, candidate models, including up to four of the predictors 152 described above in a single model (see Supplemental Table S1 for the full list of models). We did 153 not include predictors displaying multicollinearity $(r>0.70)$ in the same model (Dormann et al., 154 2013). We identified the combination of predictors that best described variations in predation 155 risk using the corrected Akaike Information Criterion (AICc) for small sample size (Burnham 156 and Anderson 2002) estimated from the library AICcmodavg (Mazerolle 2015). Models with $157 \Delta \mathrm{AICc}<2$ from the top model were considered competitive (Burnham and Anderson 2002). 158 Finally, we used the survfit function (library survival, Therneau 2015) to create survival 159 probability curves using the Kaplan-Meier survival estimates of Cox models.

160 We tested the assumption of the Cox models that the hazard function does not change over time 161 for each covariate by regressing the Schoenfield residuals across time (Hess, 1995). A significant 162 non-zero slope indicates a violation of the assumption. We confirmed that the assumption was 163 respected for each predictor variable through visual inspection of the regression of the 
164 Schoenfield residuals against time confirmed, and also for each model (cox.zph function, library 165 survival; Therneau 2015). We performed all statistical analyses in R 3.2.3 (R Development Core 166 Team 2015).

167 The experiment and field protocols were approved by the Université de Moncton Animal Care 168 Committee (permit \# 14-05), by the Department of Environment - Government of Nunavut 169 (permit \# WL-2014-039), and by the Canadian Wildlife Service (permits \#NUN-SCI-14-04).

\section{Results}

171 A total of 18 American Golden-Plover nests was found in our extensive search area of $11.7 \mathrm{~km}^{2}$

172 (1.5 plover nests. $\left.\mathrm{km}^{-2}\right)$. All of these nests were active when we started the experiment on 7 and 8 173 July. We therefore used more than a third of all available nests (seven vs. 18 nests) to run the 174 experiment.

\section{Predation risk and density of active plover nests}

176 The model that best explained variation in predation risk on artificial nests included the density 177 of active plover nests within a radius of $250 \mathrm{~m}$ around the artificial nest (Supplemental Table 178 S1). The Cox proportional hazard mixed-effects regression model indicated that the predation 179 risk increased by 1.4 -fold (coefficient $=0.87, \mathrm{SE}=0.24, P=0.0003$, hazard ratio $=2.4$; Fig. 2), 180 when we observed one active plover nest within the $250-\mathrm{m}$ radius around the artificial nest. The 181 increase was 2.4-fold (coefficient $=1.22, \mathrm{SE}=0.37, P=0.001$, hazard ratio $=3.4$; Fig. 2) when 182 there were two active plover nests within the $250-\mathrm{m}$ radius. The second most parsimonious model $(\triangle \mathrm{AICc}=1.99)$ included the effect of habitat type in addition to the density of active 
184 plover nests (Supplemental Table S1). However, the effect of habitat type on predation risk was

185 not significant $($ coefficient $=0.09, \mathrm{SE}=0.24$, hazard ratio $=1.10, P=0.7)$.

186 Predation risk and distance to the nearest active plover nest

187 To confirm the direction of the results obtained through the best fitting model shown above, we

188 also report the results of the model including the distance to the nearest active plover nest, 189 although this model had a $\Delta \mathrm{AICc}>2(\Delta \mathrm{AICc}=2.36$; Supplemental Table $\mathrm{S} 1)$. This model 190 showed that predation risk of artificial nests decreased by $20 \%$ for each additional $100 \mathrm{~m}$ further 191 away from an active plover nest $(\operatorname{coeff}=-0.21, \mathrm{SE}=0.06, P=0.0003$, hazard ratio $=0.81)$.

\section{Discussion}

193 We showed that predation risk on artificial nests increased with the density of active plover nests 194 and decreased with the distance to the nearest active plover nest during a year of low lemming 195 abundance. Contrary to our predictions, these results do not support the existence of a protective 196 effect of nesting plovers on nearby nests.

\section{Spatial variation in predation risk}

198 We predicted that predation risk would decrease with the distance to plover nests, assuming that the antipredator of the American Golden-Plovers could repel predators. Several studies showed that predation risk increases with the distance to the nest of an aggressive or territorial species (Bêty et al. 2001, Mönkkönen et al. 2007, Roos 2002, Larsen and Grundetjern 1997, Elliot 1985). For instance, Larsen and Grundetjern (1997) showed a decrease in predation risk of 
204 that there are no effects (Larsen and Grundetjern 1997: Pacific Golden-Plovers [Pluvialis fulva])

205 or even some disadvantages to nesting around a species using conspicuous antipredator

206 behaviour, especially during years of higher nest predation rates (Smith et al. 2007b). For

207 instance, nesting near an aggressive species like the Sabine's Gull (Xema sabini) increased nest

208 survival of Red Phalaropes (Phalaropus fulicarius) but only in years when nest predation rates

209 were generally low due to high lemming abundance; when lemming abundance decreased, and

210 nesting near Sabine's Gulls induced negative effects on phalarope nest survival (Smith et al.

211 2007b). These results suggest that conspicuous behaviour may attract shared predators in years

212 when the abundance of the main prey is low.

213 We also predicted that predation risk would decrease with the density of plover nests. We rather

214 observed that predation risks increase with the density of plover nests. This is not in line with

215 what has been found by Andersson and Wiklund (1978), who showed that predation risk on

216 artificial nests was higher in absence than in presence of a fieldfare pair and nearby a solitary

217 pair than a nesting colony. They attributed their results to their efficient solitary and communal

218 aggressive behaviour towards predators. Our results rather indicate that an increased density of

219 American Golden-Plover nests may attract predators. The presence of species using conspicuous

220 behaviour can attract predators (Smith et al. 2007b), and this can increase with the nest density of

221 the conspicuous species owing to the increased detectability of potential prey by predators

222 (Schmidt and Whelan 1999, Varela et al. 2007).

223 Consistent with the results of Smith et al. (2007a), we found no habitat effect on the survival of

224 the artificial nests. Powell (2001) reported that habitat characteristics were not a good predictor

225 for the nest survival of snowy plover. Yet, some studies provide evidence of a spatial 
226 heterogeneity in predator activity (Schmidt et al. 2006). For instance, Lecomte et al. (2008)

227 reported a higher predation risk in the mesic tundra compared to arctic wetlands because the

228 physical structure of wetlands reduced the mobility of foxes, the main arctic predator for

229 breeding birds.

230 Prey and predator behaviours

231 The differences between the antipredator behaviour of the American Golden-Plover and that of

232 the Black-bellied Plover could help explain why our results differ from those of Larsen and

233 Grundetjern (1997), who observed a reduced predation risk around Black-bellied Plover. In

234 addition to alarming, mobbing and distraction displays, Black-bellied Plovers attacked 50\% of

235 predators entering an area of 200-m radius surrounding their nests, respectively (Larsen and

236 Grundetjern 1997). The American Golden-Plover uses various levels of intensity of alarming,

237 mobbing and distraction displays when the predator is within 200-300 $\mathrm{m}$ from its nest (Drury

238 1961, Gochfeld 1984, Byrkjedal 1987a, Byrkjedal and Thompson 1998). That species can also

239 adopt more aggressive behaviours such as aerial attacks in some populations (reviewed in

240 Johnson and Connors 2010). Yet, aerial attacks by the American Golden-Plovers are considered

241 rare and would occur only when predators are small (Sordahl 1981, McCaffery 1982, Paulson

242 and Erckmann 1985). Because the American Golden-Plover can adopt various behaviour to deter

243 different predator species (Sordahl 1981, McCaffery 1982, Paulson and Erckmann 1985), further

244 studies should aim at determining how nest predation by different species varies with distance

245 from and density of American Golden-Plover nests.

246 When lemmings are scarce, arctic foxes increase their foraging intensity on bird nests (Bêty et al.

247 2002; McKinnon et al. 2013), and conspicuous antipredator behaviours could signal the presence 
248 of a nest to a predator in search of alternative prey (Smith et al. 2007b). In this study, we did not

249 compare the influence of American Golden-Plover nests on predation risk between years of high

250 and low lemming abundance. Thus, we cannot exclude that low lemming abundance could

251 contribute to explaining the increase in predation risk with the density of and proximity from

252 plover nests, but this remains to be tested.

253 Estimating predation risk using artificial nests

254 Artificial nests have the advantage of providing a standardized measure of predation risks. Yet, 255 predation rates on artificial nests differ from that of real nests and, therefore, they should not be 256 used to infer predation pressure on natural nests (Moore and Robinson 2004; McKinnon et al. 257 2010b). In our study, we used artificial nests to provide a controlled measure of relative 258 predation risk at various distances from plover nests, not to infer real nest success. Success of 259 natural nests is not only determined by predation risk, but by a combination of factors such as 260 nest defence behaviour (Kis et al. 2000), parental care (Smith et al. 2007a), incubation duration 261 (Schamel and Tracy 1987), nest site selection (Martin 1998), and frequency of incubation 262 recesses (Martin et al. 2000). Here, artificial nests allowed us to control for such sources of 263 heterogeneity to estimate the influence of plover nests on nest predation risk.

\section{Conclusion}

265 In conclusion, the artificial nests experiment conducted on Igloolik Island during a year of low 266 lemming abundance, does not support the existence of a protective effect of plover nests on 267 nearby nests, and in fact implies that it is considerably less safe to nest near plovers. Our results 268 bring new perspective on how the spatial distribution and composition of shorebird communities 269 may influence breeding success of arctic-nesting birds. Understanding how the composition and 
270 structure of shorebird communities generate spatial patterns in predation risks represents a key

271 step to better understand the importance of these species of conservation concern (Morrison et al.

272 2001, Gratto-Trevor et al. 2011) in tundra food webs.

\section{Acknowledgments}

274 We thank M.-C. Frenette, Amanda Taqtaq, and Mike Qrunnut for their valuable assistance in the

275 field as well as the Government of Nunavut for its logistical support. We are grateful to D.

276 Kramer and two anonymous reviewers for insightful comments on earlier versions of the

277 manuscript. 


\section{Literature Cited}

ANDERSSON, M. AND C. G. WIKLUND. 1978. Clumping versus spacing out: Experiments on nest predation in fieldfares (Turdus pilaris). Animal Behaviour 26: 1207-1212.

BÊTY, J., G. GaUthIER, E. KorpIMÄKI, AND J.-F. GIROUX. 2002. Shared predators and indirect trophic interactions: lemming cycles and arctic-nesting geese. Journal of Animal Ecology 71: 8898.

BÊTy, J., G. GaUthier, J.-F. GIROUX, AND E. KorpimäKI. 2001. Are goose nesting success and lemming cycles linked? Interplay between nest density and predators. Oikos 93: 388-400.

Burke, D. M., Elliott, K. E. N., Moore, L., Dunford, W., E. Nol, J. Phillips, S. Holmes, And K. Freemark. 2004. Patterns of nest predation on artificial and natural nests in forests. Conservation Biology 18: 381-388.

Burnham, K. P., AND D. R. Anderson. 2002. Model selection and multi-model inference: a practical information-theoretic approach, 2nd edn. Springer, New York.

Brown, S. C., H. R. Gates, J. R. Liebezeit, P. A. Smith, B. L. Hill, And R. B. Lanctot. 2014. Arctic shorebird demographics network breeding camp protocol, Version 5. Unpublished paper by U.S. Fish and Wildlife Service and Manomet Center for Conservation Sciences.

BYRKJEDAL, I. 1987a. Antipredator behavior and breeding success in greater golden-plover and Eurasian dotterel. Condor 89: 40-47.

BYRKJEDAL, I. 1987b. Short-billed dowitchers associate closely with lesser golden plovers. Wilson Bulletin 99: 494-495.

Byrkjedal, I., And D. Thompson. 1998. Tundra Plovers: The Eurasian, Pacific, and American Golden Plovers and Grey Plover. T \& AD Poyser, London.

dormann, C. F., J. Elith, S. Bacher, C. Buchmann, G. Carl, G. Carré, J. R. G. Marquéz, B. Gruber, B. lafourcade, P. J. Leitão, T. Münkemüller, C. McClean, P. E. Osborne, B. Reineking, B. SCHRÖDER, A. K. SKIDMORE, D. ZUReLl AND S. LAUTENBACH. 2013. Collinearity: a review of methods to deal with it and a simulation study evaluating their performance. Ecography 36: 027-046.

DRURY, W. H. 1961. The breeding biology of shorebirds on Bylot Island, Northwest Territories, Canada. The Auk 78: 176-219.

ELLIOT, R. D. 1985. The exclusion of avian predators from aggregations of nesting lapwings (Vanellus vanellus). Animal Behaviour 33: 308-314. 
310

311

312

313

314

315

316

317

318

319

320

321

322

323

324

325

326

327

328

329

330

331

332

333

334

335

336

337

338

339

340

341

ElLIS, D. V, AND J. Evans. 1960. Comments on the distribution and migration of birds in Foxe Basin, Northwest Territories. The Canadian Field Naturalist 74: 59-70.

EnVIRONMENT CANADA [online]. 2015. Canadian climate normals 1981-2010 Station Data. $<$ http://climate.weather.gc.ca/climate normals/results 19812010 e.html?stnID=1756 \&autofwd=1> (25 March 2015).

Forbes, G., K. Robertson, C. Ogilvie, And L. Seddon. 1992. Breeding densities, biogeography, and nest depredation of birds on Igloolik Island, NWT. Arctic 45: 295-303.

GOCHFELD, M. 1984. Antipredator behavior: aggressive and distraction displays of shorebirds, p. 289-377. In J. Burger and B.L. Olla (ed.), Behavior of marine animals. Vol. 5. Shorebirds: breeding behavior and populations. Plenum Press, New York.

Gratto-Trevor, C. L., R. I. G. Morrison, B. Collins, J. Rausch, M. Drever, And V. H. Johnston. 2011. Trends in Canadian shorebirds. Canadian Biodiversity: Ecosystem Status and Trends 2010, Technical Thematic Report No. 13. Canadian Councils of Resource Ministers. Ottawa, ON.

HAEMIG, P. D. 2001. Symbiotic nesting of birds with formidable animals: a review with applications to biodiversity conservation. Biodiversity and Conservation 10: 527-540.

HESS, K. R. 1995. Graphical methods for assessing violations of the proportional hazards assumption in cox regression. Statistics in Medicine 14: 1707-1723.

Johnson, O.W. And Connors, P.G. 2010. American Golden-Plover (Pluvialis dominica), The Birds of North America Online (A. Poole, Ed.). Ithaca: Cornell Lab of Ornithology; Retrieved from the Birds of North America Online: http://bna.birds.cornell.edu/bna/species/201 doi:10.2173/bna.201

KIS, J., LIKER, A., Szekely, T. 2000. Nest defence by lapwings: observations on natural behaviour and an experiment. Ardea 88: 155-163.

LARSEN, T., AND S. GRUNDETJERN. 1997. Optimal choice of neighbour: predator protection among tundra birds. Journal of Avian Biology 28: 303-308.

LARSEN, T., T. A. Sordahl, AND I. ByrkJedal. 1996. Factors related to aggressive nest protection behaviour: a comparative study of Holarctic waders. Biological Journal of the Linnean Society 58: 409-439.

Lecomte, N., V. Careau, G. Gauthier, And J.-F. Giroux. 2008. Predator behaviour and predation risk in the heterogeneous Arctic environment. Journal of Animal Ecology 77: 439-447.

Lecomte, N., G. Gauthier, And J.-F. Giroux. 2009. A link between water availability and nesting 
success mediated by predator-prey interactions in the Arctic. Ecology 90: 465-475.

343

LECOMTE, N., AND M.-A. GIRoux. 2015. New avian breeding records for Igloolik, Nunavut. Canadian Field Naturalist 129:194-196.

MARTIN, T. E. 1998. Are microhabitat preferences of coexisting species under selection and adaptive? Ecology, 79: 656-670.

Martin, T. E., SCOtT, J., And C. Menge. 2000. Nest predation increases with parental activity: separating nest site and parental activity effects. Proceedings of the Royal Society $B$ 267:2287-2293.

MAZERolle, M. J. 2015. AlCcmodavg: Model selection and multimodel inference based on (Q)AIC(c). R package version 2.0-3. <http://CRAN.R-project.org/package=AICcmodavg > (19 January 2016).

MCCAFFREY, B. J. 1982. Geographic variation in predator-mobbing behaviour - a hypothesis. Wader Study Group Bulletin 35: 30-30.

McKinnon, L., D. Berteaux, G. Gauthier and J. BÊTY. 2013. Predator-mediated interactions between preferred, alternative and incidental prey in the arctic tundra. Oikos, 122: 1042-1048.

Mckinnon, L., P. A. Smith, E. Nol, J.-L. Martin, F. I. Doyle, K. F. Abraham, H. G. Gilchrist, R. I. G. MORRISON AND J. BÊTY. 2010a. Suitability of artificial nests. Science 328: 46-47.

McKinnon, L., P. A. Smith, E. Nol, J. L. Martin, F. I. Doyle, K. F. Abraham, H. G. Gilchrist, R. I. G. MORRISON AND J. BÊTY. 2010b. Lower predation risk for migratory birds at high latitudes. Science 327: 326-327.

MönkKönon, M., M. Husby, R. Torngerg, P. Helle, And R. L. Thomson. 2007. Predation as a landscape effect: The trading off by prey species between predation risks and protection benefits. Journal of Animal Ecology 76: 619-629.

MoORe, R. P., And W. D. Robinson. 2004. Artificial bird nests, external validity, and bias in ecological field studies. Ecology 85: 1562-1567

Morrison, R. I. G., Aubry, Y., Butler, R.W., Beyersbergen, G.W., Downes, C., Donaldson, G.M., Gratto-Trevor, C.L., Hicklin, P.W., Johnston, V.H. And Ross, R.K. 2001. Declines in North American shorebird populations. Wader Study Group Bulletin 94: 34-38.

Nguyen, L. P., K. F. Abraham, AND E. Nol. 2006. Influence of arctic terns on survival of artificial and natural Semipalmated Plover Nests. Waterbirds 29: 100-104. 
373

374

375

376

377

378

379

380

381

382

383

385

386

387

NUeChterlein, G. L. 1981. "Information parasitism" in mixed colonies of western grebes and Forster terns. Animal Behaviour 29: 985-989.

PAULSON, D. R., AND W. J. ERCKMANN. 1985. Buff-breasted sandpipers nesting in association with black-bellied plovers. Condor 87: 429-430.

PowelL, A. N. 2001. Habitat characteristics and nest success of Snowy Plovers associated with California Least Tern colonies. Condor 103: 785-792.

QuinN, J. L., AND M. UetA. 2008. Protective nesting associations in birds. Ibis 150: 146-167.

R DeVelopment Core Team. 2015. R: A language and environment for statistical computing. $R$ Foundation for Statistical Computing, Vienna, Austria. <http://www.R-project.org/> (19 January 2016).

RICKLEFS, R. E. 1969. An analysis of nesting mortality in birds. Smithsonian Contributions to Zoology 9: 1-48.

RODGERS, J. A., JR. 1987. On the antipredator advantages of coloniality: A word of caution. Wilson Bulletin: 99:269-271.

Roos, S. 2002. Functional response, seasonal decline and landscape differences in nest predation risk. Oecologia 133: 608-615.

SChAMEL D., AND D.M. TRACY. 1987. Latitudinal trends in breeding red phalaropes. Journal of Field Ornithology 58:126-134

SCHMIDT, K. A., R. S. OSTFELD, AND K. N. SMYTH. 2006. Spatial heterogeneity in predator activity, nest survivorship, and nest-site selection in two forest thrushes. Oecologia 148: 22-29.

SChMidT, K. A. AND C. J. Whelan. 1999. Nest Predation on Woodland Songbirds: When Is Nest Predation Density Dependent? Oikos 87: 65-74.

SIMMONS, K. E. L. 1952. The nature of the predator-reactions of breeding birds. Behaviour 4: 161-171.

SMITH, P. A., H. G. GILChRIST AND J. N. M. SMITH, 2007a. Effects of nest habitat, food, and parental behavior on shorebird nest success. Condor 109: 15-31.

SMith, P. A., H. G. GILChrist, J. N. M. SMIth, E. Nol AND D. B. LANK. 2007b. Annual variation in the benefits of a nesting association between red phalaropes (Phalaropus fulicarius) and Sabine's gulls (Xema sabini). The Auk 124: 276-290. 
402 SORDAHL, T. A. 1981. Predator-mobbing behaviour in the shorebirds of North America. Wader $403 \quad$ Study Group Bulletin 31: 41-44.

404 Therneau, T. 2012. coxme: Mixed effects Cox models. R package version 2.2-5. < http://CRAN.R$405 \quad$ project.org/package=coxme $>$ (15 January 2016).

406 TherneAu, T. 2015. A Package for Survival Analysis in S. R package version 2.38-3.

$407 \quad<$ http://CRAN.R-project.org/package=survival> (15 January 2016).

408 409
Thompson, F. R, AND D. E. 2004. Differences in predators of artificial and real songbird nests: evidence of bias in artificial nest studies. Conservation Biology 18: 373-380.

Thompson, D. B. A., AND M. L. P. Thompson. 1985. Early warning and mixed species association: the Plover's Page revisited. Ibis 127: 559-562.

VARela, S. A. M., É. DANChin AND R. H. WAgneR. 2007. Does predation select for or against avian coloniality? A comparative analysis. Journal of Evolutionary Biology 20: 1490-1503. 


\section{Figure Legends}

416 Fig. 1. Location of the study area on Igloolik Island (Nunavut, Canada, 69.39 ${ }^{\circ} \mathrm{N} ; 81.55^{\circ} \mathrm{W}$ ).

417 Lower right side of the figure displays the experimental design of the experiment conducted in

418 July 2014 with artificial nests placed 30, 50, 100, 200 and $500 \mathrm{~m}$ from a focal natural plover nest.

419 Density of active plover nests within a radius of $250 \mathrm{~m}$ is shown for the artificial nest placed at

$420100 \mathrm{~m}$ from the focal natural plover nest (two active plover nests in this example).

421 Fig. 2. Kaplan-Meier survival probabilities over 12 exposure days for artificial nests with 422 varying active plover nest density (zero, one or two active nest[s] with a radius of $250 \mathrm{~m}$ around 423 the artificial nest) on Igloolik Island (Nunavut, Canada) during the summer of 2014. Each data 424 point on the curve represents the Kaplan-Meier survival estimate at time $t( \pm S E)$, which provides 425 the probability that a nest will survive past time $t$. 


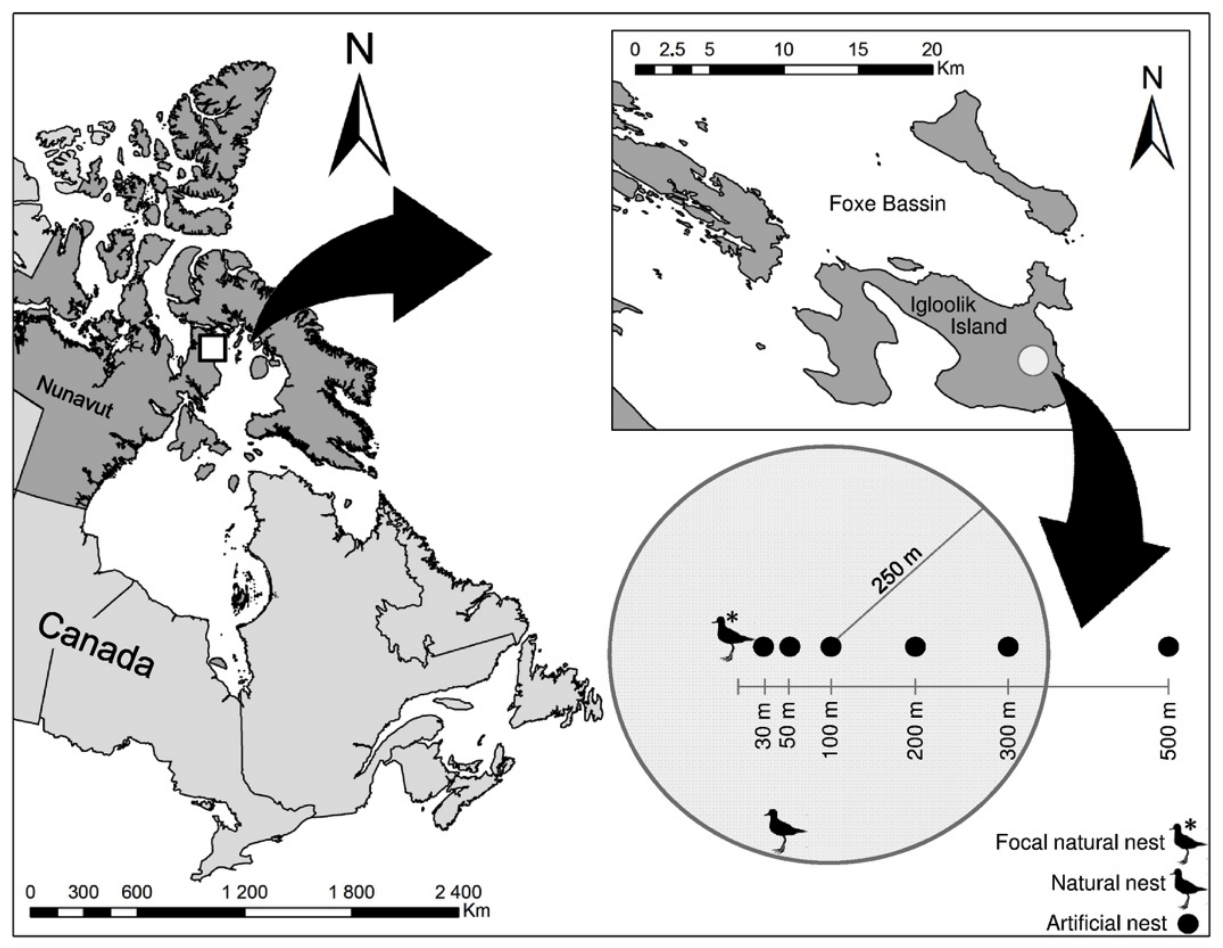

Fig. 1. 


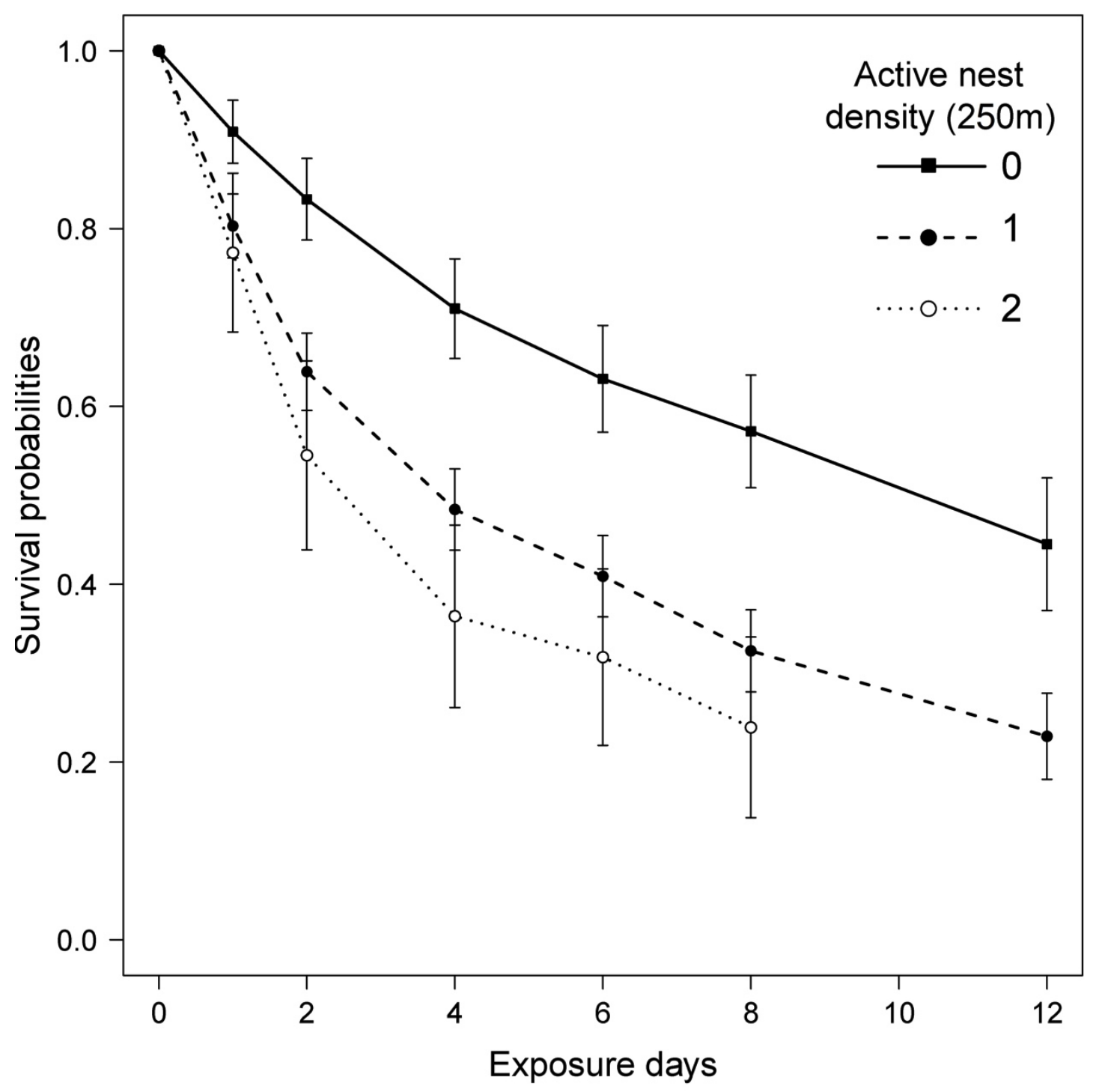

429

430 Fig. 2. 